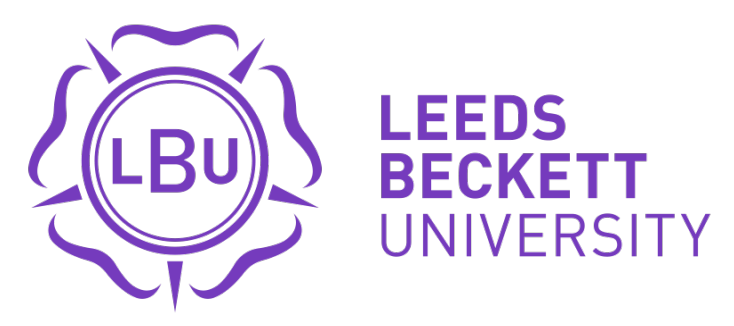

Citation:

Page, D (2016) The surveillance of teachers and the simulation of teaching. Journal of Education Policy, 32 (1). pp. 1-13. ISSN 1464-5106 DOI: https://doi.org/10.1080/02680939.2016.1209566

Link to Leeds Beckett Repository record:

https://eprints.leedsbeckett.ac.uk/id/eprint/2796/

Document Version:

Article (Accepted Version)

The aim of the Leeds Beckett Repository is to provide open access to our research, as required by funder policies and permitted by publishers and copyright law.

The Leeds Beckett repository holds a wide range of publications, each of which has been checked for copyright and the relevant embargo period has been applied by the Research Services team.

We operate on a standard take-down policy. If you are the author or publisher of an output and you would like it removed from the repository, please contact us and we will investigate on a case-by-case basis.

Each thesis in the repository has been cleared where necessary by the author for third party copyright. If you would like a thesis to be removed from the repository or believe there is an issue with copyright, please contact us on openaccess@leedsbeckett.ac.uk and we will investigate on a case-by-case basis. 


\section{The surveillance of teachers and the simulation of teaching}

\section{Dr. Damien Page}

\section{Leeds Beckett University}

Damien.Page@leedsbeckett.ac.uk

This is an author's accepted version of an article that will appear in the Journal of Education Policy. The article was accepted in its current form on 29/06/16. 


\title{
The surveillance of teachers and the simulation of teaching
}

\begin{abstract}
Just as surveillance in general has become more sophisticated, penetrative and ubiquitous, so has the surveillance of teachers. Enacted through an assemblage of strategies such as learning walks, parental networks, student voice and management information systems, the surveillance of teachers has proliferated as a means of managing the risks of school life, driven forward by neoliberal notions of quality and competition. However, where once the surveillance of teachers was panoptic, a means of detecting the truth of teaching behind fabrications, this article argues that surveillance within schools has become a simulation in Baudrillard's terms, using models and codes such as the Teachers' Standards and the Schools Inspection Handbook as predictors of future outcomes, simulating practice as a means of managing risk. And if surveillance in schools has become a simulation then so perhaps has teaching itself, moving beyond a preoccupation with an essentialist truth of teaching to the hyperreality of normalised visibility and the simulation of teaching. This article argues that surveillance - including external agencies such as Ofsted - no longer exists to find the truth of teaching, the surveillance of teachers exists only to test the accuracy of the models and codes upon which the simulation is based.
\end{abstract}

\section{Introduction}

A teacher arrives at school, swipes into the staffroom with her keycard and settles down at her desk within the open plan office as her colleagues - who arrived earlier - smile at her then look at the clock. She logs in to her PC, clicking 'OK' on the statement of permitted internet use reminding her that her activity is monitored and accesses the files containing her lesson plans for the morning lesson, entered onto the standardised lesson plan proforma that was designed by the Director of Teaching and Learning after consultation from an external inspector. After a quick check of the curriculum requirements for the topic, she prints off her last entry to the performance monitoring of her class, noting the patterns of attendance, behaviour and achievement. She walks down the glass corridor, waving at her colleagues who are already ensconced within their glass classrooms, and settles at the teacher-desk within the open plan learning space where she will facilitate learning next to the class facilitated by her Head of Department. The learning outcomes projected onto the interactive whiteboard, she begins the lesson, only marginally disturbed by the late arrival of two students who say sorry Miss but they were with the Deputy Head who was conducting a student voice session. The class settle down to student-directed learning (an external inspector in a partner school told their Executive Headteacher this was the way forward), the teacher takes pictures of each students' work and uploads it on her mobile phone to the classes' achievement website for their parents' viewing. Halfway through reviewing and recording student progress, the Headteacher arrives on a learning walk, briefly questioning her about the outcomes before chatting with students and looking through their learning journals for feedback. As she leaves, the Head reminds the teacher that her appraisal is next week and she would like her self-evaluation three days in advance. The teacher smiles and continues, making a note that she has to print the performance statistics for her year 9 group which are particularly impressive in terms of distance travelled, hopefully impressive enough to progress to the next pay point.

While teaching has always been about being watched, the surveillance of teachers is an altogether more recent activity. Where once surveillance was embodied within external agencies 
such as Ofsted (the schools inspectorate for England) inspections, one week every 3-5 years of intense scrutiny, now teachers operate in a context of normalised visibility (Page, 2015) where they are surveilled from the moment they swipe their staff card to the moment they leave the premises, the multiple strategies of surveillance working together in assemblage. This proliferation of teacher surveillance, from learning walks to parental networks, is driven by a preoccupation with risk: the risk of a poor inspection, poor exam results, poor league table ranking, negative parental attention, bad press in the media. As such, with risk the primary driver of surveillance in schools, traditional surveillance - the panoptic - has been rendered obsolete. With its rigid materiality (Bogard, 2014) the panoptic is reactive, observing before judgement in the present tense. With future risk the driving force in the contemporary school, what is needed is a means of prediction, of knowing the future as if it had already past, a means of avoiding and eliminating risk. Here is the notion of surveillance as simulation (Bogard, 1998). Drawing on Baudrillard, Bogard argues that traditional surveillance is about the present tense, it is about observing then acting in response to what is observed. For example, in traditional contexts, a CCTV operator observes a crime then alerts the police who will then respond. The time taken by the police to arrive is the primary weakness of such a strategy. Far more effective is facial recognition technology that identifies a known criminal through automated cameras that alerts the police to the location before a crime has taken place allowing the police to be on the scene before a criminal act can occur. Rather than reactive, surveillance here relies on using data about what is already known to predict future outcomes. In this example, surveillance is a product of the criminal's record, the types of crimes he/she has committed in the past which provides a means to predict the likelihood that they will commit a similar crime given the area they have arrived in. Surveillance in this case is a simulation. Where once predictive surveillance was the stuff of science fiction, a 'Minority Report' activity of literally seeing into the future to prevent negative outcomes, surveillance as simulation uses codes and models as predictors of future outcomes, simulating practice as a means of determining future events. While surveillance as simulation arose primarily from security and financial contexts, in 'liquid modernity' (Bauman, 2000) where technologies flow from context to context, increasingly it has become part of the everyday life of schools: if a teacher is graded as 'Good' in surveillance activities such as classroom observations, learning walks and student test results, it can be predicted that they will be graded 'Good' in the next inspection - following the codes set down by government and inspectorates facilitates the prediction of future outcomes.

From this perspective, this article moves the literature around performativity and surveillance forward in three key ways. Firstly, whereas the vast majority of studies of surveillance in education use panopticism as the analytical tool, this is the first article to apply the analytical framework of surveillance studies to educational contexts. Surveillance studies has moved firmly into the post-panoptic paradigm and this article reflects that shift. Secondly, the extant educational literature in this area considers surveillance within the present tense, as reactive to what is observed. This article argues that the pace of performative technologies is such that surveillance has become future-oriented instead, a proactive strategy of prediction rather than reaction, a shift that has significant implications for school leaders and teachers in terms of the way performance is evaluated and managed. Finally, whereas existing studies argue that surveillance produces teaching fabrications, this article moves beyond that position to argue that performativity has intensified to such an extent that it has gone beyond the production of fabrications, producing teaching as a simulation instead. From a Baudrillardian perspective, the 
intensification of performativity has moved teaching from a second order simulacrum - which retains a distinction between 'real' teaching and 'fabricated' teaching - to the third order of simulacra, pure simulation, a hyperreality that replaces 'real' teaching.

\section{Contemporary surveillance}

Lyon, Haggerty and Ball (2014) argue that surveillance has 'emerged as the dominant organizing practice of late modernity', a product of political and socioeconomic change since the end of the Second World War that created a preoccupation with risk (Kroener and Neyland, 2014). The result, the 'risk society' (Beck, 1992), has become solely concerned with the management and prevention of the risks it has itself produced, the risk of war, of terrorism, of poverty, of civil unrest, of a lack of international competitiveness. The risk society is therefore future-oriented, attempting to alleviate the anxiety produced at a social and personal level by intensifying surveillance. The intensification of risk-focus has been facilitated by the advances in technology; indeed, it can even be argued that the preoccupation of risk has driven the advances in technology that has created ever smaller drones, ever more remote cameras, ever more invisible means of recording of internet activity. Whether in warfare, online or in the street, surveillance is the product of risk. Similarly, the proliferation and sophistication of surveillance within schools also proceeds from a preoccupation with risk. To a large extent, risk in schools can be seen as part of the 'neoliberal risk society' (Lakes and Carter, 2011), with education positioned within notions of marketisation and competition. Here, economic anxiety blends with parental anxiety about the future for our children: without a good primary school they won't get into a good secondary school; without the right school qualifications they won't get into a highly ranked university; without the right higher education credentials they won't get into the top professions; without joining the top professions they won't be economically secure. Here, parents are required to adopt the mantle of 'the citizen as active entrepreneur of the self' (Davies and Bansel, 2007), agentively exercising their choice, a primary discourse of neoliberalism. But in education terms, this is informed choice, informed by school exam results, the result of inspections, the experiences of other parents, the higher education destinations of leavers, the marketing of success stories. As a result, the risk-anxiety of parents, required to be 'unequivocally middle class' to participate in the neoliberal scenario (ibid), promulgates the risk-anxiety within education: at a macro level there is the risk to the economic competitiveness produced by poorly educated school-leavers ill-equipped to push the nation up the various international league tables of productivity. At the institutional level, within a context of performativity and marketisation, there is the risk of slipping down league tables or attracting a poor inspection judgement - the results here are partly moral in terms of children poorly equipped for adult life and employment but also personal in terms of the job security of headteachers, and the 'disappearing' (Lepkowska, 2014) of senior leaders who fail to secure a good or outstanding inspection evaluation; the risks for teachers are equally real with increased pressure to improve leading to increased workloads or being managed out of employment. Finally, at the individual level there is the safeguarding risk, damaged children abused by predatory teachers or teachers falsely accused of abusive behaviours. As a result of risk, surveillance has intensified within schools and looming large in the educational research around surveillance is the panoptic metaphor (Bushnell, 2003; Piro, 2008; Selwyn, 2000), especially to capture the practice of teaching observations, conducted internally by senior schools leaders and externally by Ofsted (Perryman, 2009, Page, 2013). 
However, while the education literature has clung doggedly to the panoptic, contemporary surveillance studies has largely moved to an understanding of surveillance as post-panoptic, with Foucault's metaphor 'a ghost lurking' (Lyon, 2006, p10) rather than a central notion, the limitations of the panoptic becoming foregrounded by the advances in technology and social change. While the panoptic is limited by 'rigid materiality and architecture' (Bogard, 2014, p30) as well as by hierarchies, contemporary surveillance has seen a blurring of boundaries (Lyon, Haggerty and Ball, 2014). As a neoliberal product, surveillance has become decentralized, no longer solely in the hands of the state (Rule, 2007): now we are all surveillance workers (Smith, 2014) engaged in watching each other, whether reporting potential terrorist activities on a dedicated hotline or 'liking' a friend's holiday pictures on Facebook. Another central feature of post-panopticism is the democratization of surveillance. The panoptic is concerned with the powerful surveilling the powerless; in contemporary surveillance - in the synopticon to use Mathiesen's (1997) term - the powerless are increasingly engaged in watching the activities of the powerful: Edward Snowdon's leaking of military documents; the videoing on mobile phones of Eric Garner's brutal arrest that led to his death in the US. Panoptic surveillance is also limited by its specificity, the surveillance of an identified group of individuals and necessarily so as observation in the panopticon relied on only a few guards. Contemporary surveillance, increasingly automated and 'liquid' (Bauman and Lyon, 2013), has become integrated into everyday life, permitting the surveillance of everyone, not just specified groups, and not just for specific reasons - data is collected on everyone as routine. The panoptic also fails to account for willing participation in surveillance, a consequence of neoliberal preoccupations with individual competitiveness: we voluntarily share personal information with banks, online shopping outlets and social networking, we actively seek to be engaged in our surveillance from a neoliberal desire to be sorted into the 'good' rather than the 'bad' categories: the successful rather than the failure; the credit-worthy rather than the credit unworthy; the citizen rather than the terrorist; the happy rather than the sad; the aspirational rather than the economically inactive.

The transition from panoptic to post-panoptic surveillance is also evident in education and the UK provides an ideal case. In the early 2000s, arguably the pinnacle of the panoptic within schools and colleges, the surveillance of teachers was primarily enacted within teaching observations by senior leaders or by Ofsted, the schools inspectorate for England. Schools and colleges would have internal inspection weeks during which teachers would generally be told in advance when they would be observed; similarly, Ofsted at this time gave several months' notice of inspections. In both cases, teachers would have time to prepare, to hone their lesson plan and scheme of work, to cram every pedagogical strategy they could muster into the specified lesson. While lesson observation was the prime means of surveillance, there was also the introduction of performance management into schools in 2000 (DfEE, 2000), the world's biggest performance management system (Mahony and Hextall, 2001). With appraisal central, surveillance within schools - like surveillance in general - was a means of categorising and sorting (Lyon, 2003), of separating the good teacher from the bad teacher. However, with the ever increasing strengthening of neoliberalism in the last 15 years, marketisation and competition have become ever more intense in the school system producing ever more intense concerns with risk and ever more stringent mechanisms of judgement: while in 2000 Ofsted used a seven point scale to grade lessons ranging from Excellent to Very Poor, now there is the less nuanced scale of 1-4 with only Outstanding and Good acceptable - grade 3 was changed from 'satisfactory' to 'requiring improvement'; where once headteachers would be given the opportunity and support to reverse a 
poor inspection outcome, now headteachers are often forced out immediately with their schools subject to 'academisation', taken away from Local Authority control and placed within semiprivatised academy chains; school league tables have proliferated opening up schools to easy comparisons and judgements; standardised testing has equally proliferated facilitating competition and comparisons. As such, the risks for schools and headteachers are very real. Poor inspections and results mean parents exercising their choice (as far as possible) and avoiding certain schools affecting income and survival; headteachers may be sacked and forever linked to failure. Therefore, just as surveillance in general has become increasingly sophisticated and integrated into the fabric of everyday life, so has the surveillance of teachers. Where once surveillance was temporal, focused on specific times and activities, teachers now work within an environment of normalised visibility (Page, 2015). Where once control was achieved via the potential of being watched - the panoptic uncertainty - schools and colleges are now metaphorically (and often quite literally) glass organisations (Gabriel, 2005 and 2008) where surveillance is continuous and visible, with teachers aware that they are being surveilled at all times.

Contemporary surveillance within schools operates at three different levels (name withheld for anonymity): firstly there is vertical surveillance, downwards by senior leaders and external inspectors via proximal means such as lesson observations and learning walks but also remotely via CCTV and organisational design such as schools-within-schools (Lee and Ready, 2007) and small teams to facilitate detection of individual underperformance. Yet while top-down surveillance dominates the vertical category, bottom-up surveillance is increasing: students recording their teachers' outbursts on mobile phones and uploading them to YouTube or cyberstalking their teachers' Twitter feed and sharing details of their drinking and partying. Furthermore, top-down and bottom-up vertical surveillance converge in the foregrounding of student-voice, students reporting their perspective on their learning and their teachers to senior leaders. Secondly there is horizontal surveillance, embedded within peer-observation practices, ostensibly developmental but holding the potential to undermine professional autonomy (Singlehurst, Russell and Greenhalgh, 2008). There is also non-formalised peer-observation in open plan learning spaces and open plan offices, concertive control based upon 'negotiated consensus on how to shape their behaviour' (Barker, 1993, p411). Horizontal control also embraces parental surveillance as they monitor the activities and effectiveness of teachers (Crozier, 1999) within parental networks (Hassrick and Schneider, 2009): from casual visits to the school to direct teaching observations, from shared information among parent groups to 'apps' such as 'Homeroom' (https://gethomeroom.com) that allow parents to watch in real time the work and behaviour of their child (and their teachers). Thirdly there is intrapersonal surveillance, embedded within the ubiquity of reflective practice, offering senior leaders insights into practice not usually available, a continual recording of the practices of the self rendered to scrutiny in appraisals and self-evaluations. Non-reflectively, intrapersonal surveillance is also enacted via School Information Management Systems (SIMS) where teachers enter data on every aspect of their students' performance and behaviour allowing real time tracking of the effectiveness of teaching. Lastly, intrapersonal surveillance can also be found within the selfmonitoring of physical proximity to students, a product of the 'risk consciousness' (Sachs, 2004) proliferating within education, a need to be seen to be not touching children to avoid the suspicion of predation (Shakeshaft, 2013). 
What is perhaps most significant about contemporary surveillance in schools is the tense. Traditionally surveillance such as teaching inspections, as panoptic, was rooted within the present tense, designed to observe then pass judgement. In England for example, with notice of Ofsted inspections given in advance, surveillance was generally fixed; internal inspections became a dress rehearsal, a week-long collective fabrication. But times have changed: with Ofsted giving almost no notice of inspection, headteachers commit to continual Ofsted-readiness within their schools, a perpetual state of inspection anxiety that aims for good-or-outstanding practice throughout every day, every week and every year. As such, consumed by the risk of being classed as requiring improvement and the resultant disappearing senior leader, surveillance becomes evermore future-oriented. Surveillance begins to function as predictive. Not content with the present-tense of the panoptic, it seeks to attain the 'future antérieur', 'the expression of a future about which one can speak definitively because it has already past' (Genosko and Thompson, 2009, p130): if schools are sufficiently inspection-ready, good-or-outstanding in the present, headteachers can predict future outcomes - they will be good-or-outstanding when the inspectors do arrive, they will achieve good exam results, parents will be satisfied and student numbers will remain strong. Here, rather than seeing surveillance in schools as panoptic and rooted in the rigid materiality of the present, surveillance in schools can be seen as a simulation, following simulated conditions to predict future outcomes. And if surveillance in schools is becoming a simulation, so perhaps is teaching.

\section{Surveillance as simulation in schools}

As a technology of power, surveillance monitors and records as a means to control the behaviour of individuals and groups. However, drawing on Baudrillard, Bogard (1996, p8) argues that surveillance in post-industrial societies is more and that it

extends far beyond the simple idea of supervising or regulating individuals and social relations, to the creation of virtual forms of control within virtual societies, where supervision in fact may no longer be precisely a 'social' operation at all, but an imaginary projection of codes, models and cybernetic assemblage.

Pushed to its extreme, surveillance becomes a simulation. But simulation from this perspective is not about imitation or falseness or duplication or fabrication: 'it is a question of substituting the signs of the real for the real... deterring every real process via its operational double... that offers all the signs of the real and short-circuits all its vicissitudes' (Baudrillard, 1994, p2). Simulations, then, are not performances as in the common understanding of the term, they are not artifice. Instead, they are hyperreal, more real than real, designed to 'manufacture hypothetical [events] for specific control contexts' (Bogard, 2014, p31).

Traditional surveillance in society as in schools is designed to test reality, it is concerned with creating transparency. External inspections, as an archetype, were designed to evaluate the effectiveness of teaching, the 'truth' of teaching. In the panoptic era, with inspection dates given months in advance, surveillance was fixed temporally. In the run up to inspection the work of schools and colleges was a rehearsal, dressing the set, preparing for the week-long performance that would be enacted. Massive archives of paperwork - data, reports and case studies - would fill the dedicated inspector-baseroom that was meticulously decorated and peppered with expensive pot-plants and paintings. Everywhere was the smell of fresh paint and the sound. All 
for that one week, the week that would determine the reputation and brand of the institution for the next 3-5 years. In this context, a 'bad' teacher, a teacher who taught poorly for the rest of the year, could borrow lesson plans and resources from highly performing colleagues, they could spend weeks preparing fabricated schemes of work and downloading brand new e-learning activities. They could follow the senior managers' briefs on what inspectors are looking for and ensure, for that one week, that their students were all engaged, all learning, all recently assessed. They could brief their students on what to do if an inspector were to enter the classroom, what to say if they were asked about their usual lessons. This was surveillance as panoptic: teachers were aware of the potential for being observed and so put on a performance; the purpose of external inspection was to peer beneath that performance, that fabrication, to spy the 'real' quality of education that was hidden behind performance, the 'truth' of the place and the practice. The panoptic, as materially and temporally constrained, functions to see the truth of things, to separate the truth of the observed from the appearance of the observed and by doing so it preserves the duality between the real and artifice. 'Real' teaching is what happened when teachers are allowed to get on with the day job, artifice was during inspection. As such, traditional teacher surveillance was not very effective in preventing bad teaching - even bad teachers could put on a show during inspection week and if the show was really good and the inspectors couldn't peer beneath to the 'truth', that bad teacher would remain a risk. As a means of control, the panoptic often functions poorly. The panoptic is reactive: it 'notices, identifies and categorises before passing on information to the authorities' (Bogard, 1998, p36). With external agencies giving almost no notice of inspections and benchmarks and league tables continuously collecting and quantifying data and parents endlessly probing via their networks, surveillance is no longer rooted in the present. What is required then is a means of prevention, a means of identifying the bad teacher and his or her poor practice before they start affecting students' learning and school results. This has become the contemporary aim of surveillance as it becomes driven by the 'imaginary' in Bogard's terms, with an aim to produce control that passes 'from a logistics of inspection or perception... to a logic of prospection, from watching to anticipation, from surveillance to simulation' (Bogard, 1996, p55). Put simply, it is about shifting the focus from what is to what will be given the present conditions. In practical terms, traditional surveillance strategies such as annual internal inspections gave teachers the opportunity to "play the game' and put on a show of what the observers wanted to see. The problem with this for headteachers is that this made it impossible to accurately predict outcomes: fabrications are not an effective predictor of good exam results or a good inspection outcome. Based only upon internal inspections, headteachers could quickly become unstuck and find themselves leaders of 'failing' schools. As such, schools are now required to be 'inspection-ready' at all times, not just during the internal inspection week. Inspection-readiness in surveillance terms is a simulation. And if the simulation is accurate enough, if it mirrors the conditions of a real Ofsted inspection accurately enough, it allows headteachers to predict future outcomes, to be able to predict the inspection outcome they will achieve.

For Baudrillard (1994, p16), simulation is "characterised by a precession of the model, of all models based on the merest fact - the models come first'. In teaching, in an effort to manage risk and weed out the bad apples before they cause damage, the model that is produced is of a Goodor-Outstanding teacher, a model that draws on what is known about effective teaching, from academic research to publically available reports, from narratives of students who moved from an E grade to an A, from headteachers' perception of their own practice to the sharing of good 
practice from other schools. What is simultaneously produced is a model of a bad teacher, the diametric opposite of the good teacher, who similarly may be designed in terms of practice, behaviours and outcomes. The goal is the same as traditional panoptic surveillance, to categorise and to separate the good from the bad teacher. The difference is that the model is a simulation produced in advance, in the future-past tense, so that the bad teacher can be managed (or 'managed out') before they do damage. The 'simulation model structures the event's production and meaning, and passes judgement in advance' (Bogard, 2014, p36). Put simply, if a teacher is considered unsatisfactory during the simulation of inspection-readiness, rather than allowing them to risk damaging the future inspection outcome, they can be disciplined or, more commonly, offered a 'compromise agreement' (Page, 2015).

But humans are difficult to predict and so simulated surveillance in schools is not concerned with teachers themselves. What is of concern is their 'data double' (Haggerty and Ericson, 2000). Data doubles are our virtual selves created by collating data drawn from the expanse of surveillant mechanisms. In general society, our data doubles are assembled from our credit reports, our shopping habits, our internet searches, our key strokes, our social networking, our travel patterns, all the information that is collected about us in our everyday lives. From this, interested parties can predict when we will repay a loan, what kind of products we are likely to buy and, at the other extreme, whether we are a risk to the security of the country. Our data doubles are therefore essential to the function of surveillance as simulation - they allow predictions to be made about us. Similarly, predictions about the future are made by analysing the data doubles of teachers: from teachers uploading statistics on pupils' behaviour and achievement to grades for lesson observations to exam results to student evaluations, teacher performance is broken down into discrete units of data before being reassembled into a data double. While human teachers are unpredictable, the data double of teachers becomes highly predictable with performance in inspection and exams determined in advance. Just as the model of Terrorist can lead to the apprehension of a suspect before a terrorist incident, so the matching of a data double to the model of Inadequate teacher can lead to disciplinary action or a compromise agreement before the incompetent can impact upon exam results or an inspection. Conversely, if the data double accords with the model of Outstanding teacher, progression up the payscale will result, with the promise of enhanced visibility - the beatific as spectacle (Gabriel, 2008) - that will attract a better external evaluations and enhanced parental satisfaction.

\section{Models and codes}

If simulated surveillance in schools is based upon models, central to this are a nation's teaching competence standards. In the UK, these are the Teachers' Standards (DfE, 2013), the codification of pedagogical and behavioural practices that define what teaching is expected to be, a blueprint of Teacher that is embedded within performance management practices within schools: teaching observations are evaluated against them; teachers will review their own performance against them; appraisals will set targets based upon them; the National College for Teaching and Leadership disciplinary panels will use them as a basis for their judgements. The Teachers' Standards provide the perfect example of surveillance as simulation - by positioning them as central to teaching, they provide the model of how and what teachers should be. However, at the organisational level, the primary code that governs teaching - even more important in risk terms - is the Ofsted framework, the School Inspection Handbook (Ofsted, 2015) that codifies how schools will be inspected, how judgements will be made and the criteria 
upon which those judgements will be made. While the Teachers' Standards are embedded into the performance management of teachers, the Ofsted framework models the performance of the entire school, from leadership and management to lesson observations, providing grade descriptors from Outstanding to Inadequate. As such, they are more nuanced than the Teachers' Standards that offer the minimum level of performance expected by teachers; the Ofsted code provides gradation of effectiveness.

Both codes are not a matter of the present, they are about prediction, they set the pattern by which the future can be ascertained. If schools follow the code accurately enough, outcomes can be predicted as if the future has already happened. If adherence to the codes of effective teaching will secure a good-or-outstanding Ofsted grade, improving exam results, satisfied parents and job security for the senior leadership in the future then the model becomes paramount. Surveillance then becomes a means of monitoring accurate adherence to the codes. A learning walk may look for whether teachers 'establish a safe and stimulating environment for pupils, rooted in mutual respect' (DfE, 2011, p10); parents may determine through their networks whether teachers are 'ensuring that personal beliefs are not expressed in ways which exploit pupils' vulnerability' (ibid, p14); teachers' reflective practice may observe 'proper boundaries appropriate to a teacher's professional position' (ibid, p14); analysis of the data entered by teachers may allow the Headteacher to see whether pupils are making 'substantial and sustained progress throughout year groups across many subjects' (Ofsted, 2015, p 70). From a Baudrillardian perspective, these codes are not designed to be used as a tool to differentiate between the real and the false as the panoptic once did, they are designed to produce the subject in advance. The exercise of power, reproduced by codes and models, becomes predictive rather than present tense: schools are given the codes by government to create the teachers the government want to see in the future. Surveillance, rather than being a means to peek behind the artifice to determine reality, becomes simulation instead. Throughout all three levels of surveillance within schools (name withheld for anonymity), the vertical, the horizontal and the intrapersonal, it is not teachers or schools being monitored but the effectiveness schools in reproducing the Standards and the Framework.

From this point of view, Ofsted do not exist to try to peer beneath the mask of Outstanding; the purpose of inspection is no longer to differentiate between what is performed and what is true; the purpose of Ofsted is to check the accuracy of the model, to check that the simulation of surveillance is accurate. Evidence of this shift of purpose can be found in a 2014 Ofsted communication providing 'clarification for schools' (Ofsted, 2014) that removes a great deal of the prescription of previous years: inspectors now do not require lesson plans, there is no specification of forms of planning, they do not grade individual lessons, there is no expectation of frequency or quantity of work in pupils books and so on. Now, schools provide the codes and the models for the simulation extrapolated from the central codes, the Teachers' Standards and the School Inspection Handbook; Ofsted then check the effectiveness of the models, they check the efficacy of learning walks, unlimited teaching observations, teacher-uploaded data, student voice, parental feedback, exam results, benchmarks, all of the strategies of surveillance that create the simulation.

\section{From fabrication to simulation}

In the early 2000s, one theme that emerged (and has remained constant in the educational literature) concerning surveillance was that of its impact upon the authenticity of teaching 
practice with the 'act of teaching and the subjectivity of the teacher ... both profoundly changed within the new management panopticism' (Ball, 2003, p219). Under the panoptic gaze, Ball argued that teachers produced a spectacle 'which is there simply to be seen and judged' (Ball, 2000, p7), a performance in every sense of the word that was designed to meet the criteria upon which inspections functioned. Under the panoptic gaze, teaching became a fabrication, a performative response to the act of inspection-surveillance that separated the real teacher from the fabricated teacher, the reality of teaching from the fantasy of teaching, a set of 'dualisms or tensions... between belief and representation' (ibid). Ball's conception of the fabrication of teaching as a response to surveillance proved highly influential and underpins a number of studies of performativity and inspection (Taylor Webb, 2007; Webb, Briscoe and Mussman, 2009; Keddie, Mills and Pendergrast, 2011; Courtney, 2014), each highlighting the ontological anxiety created within teachers by fabricating: the subordination of professional autonomy and judgement to the requirements of performative regimes, the 'structural and individual schizophrenia of values and purposes' (Ball, 2003, p223) and the concomitant meaninglessness of inauthentic practice. From this perspective, schools and colleges became places of artifice under the panoptic gaze with teachers offering idealised performances to be measured and judged, complicit in the fabrication of performativity, with the observers, the inspectors, equally as complicit in the knowledge that they were observing fabrications rather than 'authentic' practice.

However, the notion of fabrication in teaching was a result of understanding surveillance in schools as panoptic; contemporary surveillance in schools is explicitly post-panoptic. The preemptive nature of contemporary surveillance signals a move to the third order of simulacra according to Baudrillard. The first stage of the evolution of simulacra sees image as a basic reflection of reality, a true likeness. The second stage 'masks and perverts a basic reality' (Bogard, 1998, p 11), it becomes deceptive, manipulative, ideological. In the third stage, within the information technology age, the image become a simulation fully and masks the absence of a reality:

the third [stage] inaugurates an era in which it becomes increasingly difficult to separate the realms of the true and the false, appearance and reality, secrecy and transparency. This for Baudrillard is our own era, where the circulation and dissemination of signimages dominate, but rather than being 'false' images, now have the function of concealing the fact that reality itself is absent behind its representation (Bogard, ibid, p11).

From this point of view, simulation has no reality any more; or rather, it is more real than real, it is hyperreal. While in the second order of simulacra panoptic surveillance functioned to probe the pretence or the mask that hid reality, in the third order - pure simulation - there is no essential reality to hide. The signs of the real are all that exist, the double of what was once real is what is encountered, the 'data double' of Haggerty and Ericson (2000). There is no question of the accuracy of the representation - what is significant is not the 'reality' of the information. The data double becomes what is significant and facilitates the simulation of surveillance. Simulation therefore produces a 'reality effect' that foregrounds the 'redundancy of the real as a possible signified' (Bogard, 1996). 
Fabrication, performance-practice, was an attempt to produce the ideal (false) image of teaching for the benefit of inspectors who sought to pick away to find the real quality of teaching; fabrications were second order simulacra. In the school as simulation, within the third order of simulacra, the real is redundant; the simulation has replaced the real, it has become hyperreal. There is no significant essentialist real in teaching anymore from a simulation perspective, there is only the simulation. What is real - what is valued, what is measured and what is judged - is not the teachers but their data-doubles. Teachers are their input of student performance data; they are their students' punctuality records; they are their observable teaching during learning walks and their 'informal' teaching grade; they are the perceptions of children in student voice collection activities; they are their ratings on www.RateMyTeachers.com; they are their reflective practice reported in appraisals; they are their participation in peer-observation schemes. They are abstracted and reassembled as quantifiable units of measurement that can be categorised and sorted and evaluated against the model and codes of the Teachers' Standards and the inspection framework, units that facilitate the prediction of inspection outcomes and league tables. Teaching is not fabricated in the contemporary school, it is simulated. Fabricated teaching is temporal, present tense, rooted in time to the moments when under the gaze; as such, fabricated practice is ineffective at managing risk, the contemporary preoccupation of school leaders. Simulated teaching, however, is future oriented, producing truth in advance by verification of the model, therefore perfectly designed to manage risk. Under the panoptic regime, a teacher may have produced a fabrication during an internal inspection and may have performed well, the headteacher may have been unable to peer beneath the artifice at the 'truth' of their teaching ability. That headteacher may retire to her office and add a ' 2 ' or 'Good' next to the teacher's name in the file of inspection preparation. However, the artifice may have crumbled for that teacher during the real inspection, the inspector may have peeked behind the façade and detected 'Unsatisfactory'. The limitations of the panoptic are clear. In the contemporary school, within the surveillant assemblage, the simulation of surveillance, fabrications are redundant. With visibility normalised and data collected continually vertically, horizontally and intrapersonally and reassembled into a data double, fabrications fool nobody and so become redundant. Instead, teaching is no longer a duality of real and false, it has itself becomes a simulation.

\section{Nostalgia and normality}

By retaining the essential difference between true and false, fabrications created 'tensions between belief and representation', a 'structural and individual schizophrenia of values and purposes' (Ball, 2003) within teachers. Under the panoptic gaze, teachers experienced ontological anxiety arising from their desire to be real, truthful and authentic in their teaching and the requirement of the performative system to create spectacles. But what of teachers working within the contemporary simulation? Ontological anxiety arises from retaining the distinction between reality and fabrication, it retains the pull towards the truth of teaching. However, when the reality of teaching can be seen as simulation, when perpetual surveillance has rendered 'real' teaching redundant, ontological anxiety is similarly rendered redundant. If teaching is a simulation, that is the real or rather the hyperreal.

For long-serving teachers, those with memories of the life under the panoptic regime when there was a difference between real and fabrication, there are two choices: firstly there is exit, whether voluntary when the ontological anxiety becomes too much, or involuntary via competency 
procedures or compromise agreements when adherence to the models and codes becomes impossible; secondly there is acceptance of the hyperreality of surveillance as simulation and nostalgia: 'when the real is no longer what it was, nostalgia assumes its full meaning' (Baudrillard, 1994, p6) and voices hark back to the golden age of professional autonomy, professional judgement, freedom within the classroom, as referents of the real of teaching that has disappeared. The nostalgic then drives the "panic-stricken production of the real and of the referential' (ibid p7), the creation of simulacra such as the College of Teaching in the UK that

will be led by teachers, enabling the teaching profession to take responsibility for its professional destiny, set its own aspirational standards... the College will demonstrate a deep commitment to high professional standards, continuing professional development and evidence-informed practice (Claim your College, 2015).

The proposal for the College nostalgically seeks to retrieve the real, the truth of professionalism. In an act of occupational amnesia that resurrects the discourse accompanying the creation of the General Teaching Council for England (GTCE) - 'an aspiration of teachers for more than 150 years' (Kirk, 2000) - the drive for a College of Teaching seeks to similarly resurrect the real of teaching, to prise teaching from the performative simulation and finally, once and for all, concretise the professionalism of teaching. Yet what professional bodies offer is not an alternative to simulation, they offer an alternative simulation, another set of professional standards - 'high professional standards' - another model of idealised Teacher against which teachers can be measured only this time, unlike the GTCE, teachers will need to sign up voluntarily, they will opt into a transactional form of intrapersonal surveillance, comforted by the simulacrum of 'independence'.

To new teachers however, surveillance as simulation is the only reality. There is no distinction between the real and the false of teaching, there is only the hyperreal. Teachers who enter the profession now have no experience of practice-privacy, no experience of uninterrupted autonomy in the classroom. Not only are they a product of the Teachers' Standards and the Ofsted framework, their practice is a product of the national curriculum, standardised lesson plans and schemes of work, normalised patterns of marking and feedback, a whole host of models and codes intended to produce teaching in advance. Surveillance then monitors the effectiveness of the code. But the headteacher popping into the class through the doorless doorway is not unusual for the new teacher; regularly entering performance information about their classes into SIMS is no intrusion; knowing that their students will be giving their evaluations to senior leaders is not unusual. Where once surveillance was an affront to the teaching profession, an intrusive strategy of performativity, now it is routine, the everyday, the normal - it has become the hyperreality of teaching. New teachers enter a context of normalised visibility where there is no differentiation between observed practice and unobserved practice, there is no anxiety arising from the potential for surveillance, visibility is normalised rather being than an event. And the normalisation process is facilitated by the drive to change the initial teacher training (ITT) landscape. IN the UK for example, where traditionally ITT was the primary responsibility of universities, since 2010 the drive has been to make teacher training schools-based through 'School Direct' (see Jackson and Burch, 2015), with universities offering input rather than management of the process. Here, trainees recruited, trained and managed by schools and are distanced from more critical approaches to teaching and education, moved away from historical, social and political 
contexts provided by academics. Instead, teacher training become more exclusively practice based, learning within the very contexts of performativity and surveillance which form the basis of school life. In a schools-based teacher training context, there is no question of betrayal of principles, of 'giving up claims to authenticity and commitment' (Ball, 2000), there is no real and no fabrication: there is only the hyperreality of perpetual surveillance as simulation. And if there is no distinction, no betrayal, there can be no ontological anxiety. Teachers become simulated.

\section{Conclusion}

While the language of prediction may conjure science fiction images of machines that can see into the future, surveillance as simulation is very real and embedded within the practice of schools. With the government, parents and headteachers all concerned with future risks, simulated surveillance becomes the priority for senior schools leaders, preoccupied with future outcomes expressed in exam results, league tables, parental satisfaction and, most importantly, inspection results. It is not enough for headteachers to prepare for future outcomes, they need to ensure their schools are simulating future outcomes. Schools must be inspection-ready, perpetually embodying the characteristics of good-or-outstanding laid down in the external inspection framework. Teachers must be exemplifications of the Teachers Standards, exceeding the minimum requirements at all times. Schools must be endlessly drilling students for exams, testing continuously so that future results can be known. The result is that teaching has become a simulation - not in the general sense of being a rehearsal - but in the sense that the simulation has replaced what the profession once considered real with its notions of autonomy and individual judgement. The traditional, panoptic strategies of surveillance in schools of course affected teaching practice but it was for limited periods, for the week of inspection when teachers would produce fabrications designed to manipulate evaluations. Simulated surveillance, the conjoining of multiple techniques into a surveillant assemblage, has had a far more dramatic impact.

\section{References}

Ball, S. J. 2000. "Performativities and fabrications in the education economy: towards the performative society?" The Australian Educational Researcher 27(2): 1-23.

Ball, S. 2003 "The teacher's soul and the terrors of performativity". Journal of Education Policy 18(2): 215-228

Barker, J. R. 1993 "Tightening the iron cage: concertive control in self-managing teams". Administrative Science Quarterly 38 (3): 408-437

Baudrillard, J. 1994 Simulacra and Simulation. Michigan: University of Michigan

Bauman, Z. 2000 Liquid Modernity. Cambridge: Polity

Bauman, Z. and Lyon, D. 2013. Liquid Surveillance. Cambridge: Polity Press

Beck, U. 1992. Risk society: Towards a new modernity (Vol. 17). New York: Sage

Bogard, W. 1996 The simulation of surveillance: Hypercontrol in telematics societies. Cambridge: Cambridge University Press

Bogard, W. 2014 "Simulation and post-panopticism". In Routledge Handbook of Surveillance 
Studies, edited by Kirstie Ball, Kevin Haggerty and David Lyon, p30-37, Oxon: Routledge

Bushnell, M. 2003 "Teachers in the schoolhouse panopticon: Complicity and resistance". Education and Urban Society 35(3): 251-72

Claim your College 2015 "Claim your College: the profession's new College of Teaching. A proposal for start-up support". Accessed 18 June 2015: http://www.claimyourcollege.org/wp-content/uploads/2015/02/College-of-teachingexpression-of-interest.pdf

Courtney, S. J. 2014. "Post-panopticism and school inspection in England". British Journal of Sociology of Education. DOI:10.1080/01425692.2014.965806

Crozier, G. 1999 "Parental involvement: who wants it?" International Studies in Sociology of Education 9(3): 219-238.

Davies, B. and Bansel, P. 2007. Neoliberalism and education. International Journal of Qualitative Studies in Education 20 (3): 247-259

DfE 2011 “Teachers' Standards". Department for Education. Accessed 16 June 2015: https://www.gov.uk/government/uploads/system/uploads/attachment data/file/301107/Teac hers Standards.pdf

DfEE 2000 Performance Management in Schools: Performance Management Framework. London: Department for Education and Employment

Gabriel, Y. 2005 "Glass cages and glass palaces: Images of organization in image-conscious Time”. Organization 12(1): 9-27

Gabriel, Y. 2008 "Spectacles of resistance and resistance of spectacles". Management Communication Quarterly 21(3): 310-326

Genosko, G. and Thompson, S. 2009 "Tense theory: the temporalities of surveillance". In Theorizing Surveillance, edited by David Lyon, Cullompton: Willan

Haggerty, K and Ericson, R. 2000 "The surveillant assemblage". British Journal of Sociology 51 (4): 605-622

Hassrick, E. M., and Schneider, B. 2009 "Parent surveillance in schools: A question of social Class". American Journal of Education 115(2): 195-225.

Jackson, A. and Burch, J., 2015 "School Direct, a policy for initial teacher training in England: plotting a principled pedagogical path through a changing landscape". Professional Development in Education. Online: http://www.tandfonline.com/doi/abs/10.1080/19415257.2015.1052090

Keddie, A., Mills, M., and Pendergast, D. 2011 "Fabricating an identity in neo-liberal times: performing schooling as "number one'". Oxford Review of Education 37(1): 75-92

Kirk, G. 2000. "The general teaching council for England". School Leadership and Management 20 (2): 235-46.

Kroener, I. and Neyland, D. 2014. "New technologies, security and surveillance". In Routledge Handbook of Surveillance Studies, edited by Kirstie Ball, Kevin Haggerty and David Lyon, 141-148. Routledge: Oxon

Lake, R. and Carter, P. 2011. Neoliberalisn and education: an introduction. Educational Studies: A Journal of the American Educational Studies Association 47 (2): 107-110

Lee, V. and Ready, D. 2007 Schools Within Schools: Possibilities and Pitfalls of High School Reform. New York: Teachers College Press

Lepowska, D. 2014. "A poor Ofsted report could lead to headteachers being 'disappeared"'. The 
Guardian. Accessed January 212015

http://www.theguardian.com/education/2014/mar/11/heads-poor-ofsted-report-dismissalshortages

Lyon, D. 2003. "Surveillance as social sorting". In Surveillance as Social Sorting:

Privacy, Risk and Digital Discrimination, edited by David Lyon, 13-30. London:

Routledge

Lyon, D. 2006 "The search for surveillance theories". In Theorizing surveillance, edited by David Lyon, 3-20. London: Routledge

Lyon, D., Haggerty, K. and Ball, K. 2014 "Introducing surveillance studies". In Routledge Handbook of Surveillance Studies, edited by Kirstie Ball, Kevin Haggerty and David Lyon, 1-12. Routledge: Oxon

Mahony, P. and Hextall, I. 2001 "Performing and conforming". In The Performing School: Managing Teaching and Learning in a Performance Culture, edited by Denis Gleeson and Chris Husbands, London: Routledge Falmer

Mathiesen, T. 1997. "The viewer society: Michel Foucault's panopticon revisited". Theoretical Criminology 1 (2): 215-234

Ofsted 2014 School inspection - clarification for schools. Accessed 16/06/15: https://www.gov.uk/government/publications/ofsted-inspections-clarification-for-schools

Ofsted (2015) School inspection handbook. Accessed 16/06/15: https://www.gov.uk/government/uploads/system/uploads/attachment_data/file/391531/Sc hool_inspection_handbook.pdf

Page, D. 2011 "From principled dissent to cognitive escape: managerial resistance in the English further education sector". Journal of Vocational Education \& Training 63(1): 113

Page, D. 2013 "The abolition of the General Teaching Council for England and the future of teacher discipline". Journal of Education Policy 28(2), 231-246

Page, D. 2015 " The visibility and invisibility of performance management in schools". British Educational Research Journal, Online First: DOI: 10.1002/berj.3185

Perryman, J. 2009 "Inspection and the fabrication of professional and performative processes". Journal of Education Policy 24(5): 611-31

Piro, J. 2008 "Foucault and the architecture of surveillance: Creating regimes of power in schools, shrines, and society". Educational Studies 44(1): 30-4

Rule, J. 2007. "Social control and modern social structure". In The Surveillance Studies Reader, edited by Sean Hier and Josh Greenberg, 19-27. Berkshire: Open University Press

Sachs, J. 2004 "Watching yourself and others: touch, personal space and risk of harm in the Classroom". Paper presented at the AARE ASnnual Conference, Melbourne, 2004

Selwyn, N. 2000 "The National Grid for Learning: Panacea or panopticon?" British Journal of Sociology of Education 21(2): 243-55

Shakeshaft, C. 2013. "Know the warning signs of educator sexual misconduct". Phi Delta Kappa 94(5): 8-13

Singlehurst, D., Russell, J., and Greenhalgh, T. 2008. "Peer observation of teaching in the online environment: an action research approach". Journal of Computer Assisted Learning 24(5): 383-393.

Smith, G.J.D. 2014. "Surveillance work(ers)". In Routledge Handbook of Surveillance Studies, edited by Kirstie Ball, Kevin Haggerty and David Lyon, Routledge: Oxon

Taylor Webb, P. 2007 “Accounting for teacher knowledge: Reterritorializations as epistemic 
Suicide". Discourse: Studies in the cultural politics of education, 28(2): 279-295. Webb, P. T., Briscoe, F. M., and Mussman, M. P. 2009 "Preparing Teachers for the Neoliberal Panopticon".. Educational Foundations 23 (1): 3-18 